\title{
$\mathrm{CSCL}$ 환경에서 조정지원스크립트 개발 및 효과
}

\author{
김수현 ${ }^{*}$ \\ ${ }^{1}$ 거제대학교 유아교육과

\section{The Effects and Development of Coordination Supporting Script in CSCL}

\author{
Soo hyun, $\mathrm{Kim}^{1^{*}}$ \\ ${ }^{1}$ koje collage Early Childhood Education
}

요 약 본 연구의 목적은 $\mathrm{CSCL}$ 에서 조정활동을 지원하는 조정지원스크립트를 개발하고 효과를 검증하는 것이다. 선행연구와 CSCL 도구를 분석하여 거시적 스크립트 설계원리와 실행원리를 도출하였고, 역할 분담과 관련된 문헌 분석을 통해 미시적 스크립트 설계원리를 도출하여 조정지원스크립트를 개발하였다. 개발된 조정지원스크립트를 $\mathrm{CSCL}$ 환경에 적용하여 그 효과를 검증한 결과, 조정지원스크립트는 학습활동(공유정신모형)에 유용한 효과가 있는 것으로 분석되었다. 본 연구의 결과는 거시적 스크립트와 미시적 스크립트를 이용한 연구와 효과적인 협력학습 방법 을 모색하는 교육현장에 의미 있는 시사점을 제공할 것이다.

\begin{abstract}
The goal of this research is to development a coordination supporting script in CSCL and tried to measure of coordination supporting script's effectiveness. Therefor, in this research, after derive macro-script design principle and activity principle from former study and CSCL tool, after derive micro-script from role sign several reference, and then based on those principle developed coordination supporting script. As providing coordination supporting script or not, there will be the sense making difference of effectiveness of coordination supporting script in learning activity(shared mental model). The result of this study may have implication for the research on macro-script and micro-script and educational practice.
\end{abstract}

Key Word : CSCL, coordination supporting script, shared mental model.

\section{1. 서론}

CSCL(computer-supported collaboration learning: 이하 $\mathrm{CSCL}$ )의 목적은 학습자간 상호작용을 촉진하고, 집단차 원의 성과를 높이기 위하여 협력적 탐구활동이 잘 일어 나게 하는 데 있다. 협력학습활동의 결과로서 공유정신모 형이 만들어지고 이를 다시 실제 현장에 적용함으로써 공유정신모형의 정제와 재구성을 반복하는 선순환 구조 를 만드는 데 그 의의가 있다. 공유정신모형이란 팀원들 이 과제, 하위과제, 과제 목표, 과제 수행 단계 및 역할에 관한 공통적으로 가지고 있는 공유된 생각을 의미한다
[19]. 이러한 공유정신모형을 구축하기 위해서는 무엇보 다 커뮤니티 내에서 해결해야 할 과제가 무엇인지 정의 하고, 해결하기 위한 계획을 세우고, 진행사항을 점검하 고, 필요한 정보를 탐색하거나 인출하고, 저장하는 등의 조정활동이 필요하다[6].

특히, 과제수행의 초기단계에서 시간관리, 업무분장, 개별지식의 통합, 개인단위의 작업과 공동작업의 적절한 조화 등을 조정하는 과정이 필요하며[12], $\mathrm{CSCL}$ 환경에 서는 더욱 그러하다[9]. 왜냐하면 CSCL 환경에서는 학습 자들이 컴퓨터 인터페이스를 다루는데 과도하게 긴장할 수 있고, 면대면 환경보다 이용가능한 의사소통 방법이

*교신저자 : 김수현(shkim@koje.ac.kr)

접수일 11년 07월 13일수정일 (1차 11년 09월 05일, 2차 11년 09월 27일)

게재확정일 11 년 10 월 06 일 
한정되기 때문이다[1]. 그러므로 CSCL 환경에서의 학습 은 조정활동에 대한 지원이 필수적이다. 이에 본 연구에 서는 $\mathrm{CSCL}$ 에서의 조정활동에 대한 지원 전략으로 조정 지원스크립트를 제안하고자 한다.

스크립트는 협력학습을 위해 사용되는 지원도구이자, 학습자들이 수행해야 할 역할과 활동들을 사전에 구성하 여 안내하는 시나리오라고 할 수 있으며[3], 학습에 필요 한 활동들에 초점을 맞추며 주제에서 벗어난 이야기를 줄이는 데 목적을 둔다[10]. 따라서 CSCL 환경에서 조정 지원스크립트를 제공한다면 과제 해결 맥락에서 벗어나 는 것을 예방하고, 효과적인 조정활동이 일어나게 하여 성공적인 협력학습을 지원할 수 있을 것이다. 조정지원스 크립트의 긍정적인 효과는 선행연구[12,14]에서 이미 검 증된 바 있다.

위의 선행연구들에서는 스크립트 수준을 거시적 스크 립트와 미시적 스크립트로 구분하여 제시하면서, 거시적 스크립트의 효과성을 검증하였다. 거시적 스크립트란 과 제의 목표 및 하위목표, 과제 전략, 자료 수집 및 통합 전 략, 과제 내용, 팀원들의 역할, 팀의 계획 등의 조정 활동 을 지원을 의미한다[4]. 거시적 스크립트는 과제를 단순 화하고 학습자들 간의 조정활동에 필요한 노력을 줄여줌 으로써 협력에 대한 부하를 낮추고, 이로 인해 협력 활동 참여와 과제 관련 상호작용을 증진시킬 수 있도록 지원 한다. 미시적 스크립트란 과제 내용에 대한 인지적 프로 세스를 촉진을 지원하고, 커뮤니케이션 활동을 지원하는 것을 의미한다[4]. 즉 과제 내용의 핵심 이슈나 아이디어 에 초점을 맞추어 인지적 노력을 집중하도록 함으로써 공유정신모형 구축에 기여하는 생산적 상호작용을 증진 을 지원한다. 거시적 스크립트는 교육적 모델 (pedagogical models)로서 그룹에 의해 수행될 일련의 연 속적 활동을 의미하며, 미시적 스크립트(micro-scripts)는 대화적 모델(dialogue models)을 의미한다.

$[3,12,14]$ 의 연구 결과에서 보면 거시적 스크립트 제공 이 상호작용의 양에는 유의한 차이를 보였지만, 상호작용 의 질에 있어서는 유의한 차이가 없었다. 이러한 결과는 거시적 스크립트의 한계를 지적한 것으로 $\mathrm{CSCL}$ 환경에 서 조정지원스크립트가 공유정신모형 구축에 긍정적인 영향을 미치기 위해서는 거시적 스크립트와 미시적 스크 립트를 함께 제공하야 함을 지적한 것이다. 이에 본 연구 에서 조정활동을 위한 거시적 스크립트와 미시적 스크립 트를 균형 있게 설계하고 개발하고자 한다.

\section{2. 조정지원스크립트 개발 전략}

\section{1 거시적 스크립트 개발 전략 도출}

거시적 스크립트 개발 전략은 기존의 조정지원환경의 설계 및 실행원리를 분석하여 도출하였다. 왜냐하면 거시 적 스크립트는 과제 수행의 일련의 연속된 활동을 의미 하기 때문에 기존의 조정지원도구의 과제 수행에 대한 단계, 스케폴딩 등을 분석하면 거시적 스크립트 전략을 도출할 수 있기 때문이다. 분석된 조정지원환경은 SIBYL, CSILE, CoVis, C-map(Concept Map)이며, $[2,5,7,12,16,18]$ 의 문헌을 분석하여 설계원리와 실행원리 를 도출하였다.

SIBYL은 [11]이 개발한 도구로서, 의사 결정 지원 도 구이다. 대안에 대해 지지하거나 반대하는 의견을 외재적 으로 표상하는 할 수 있도록 지원하고 있다. CSILE은 [13]이 개발한 도구로서, 협력활동을 지원하는 네트워크 기반 학습환경이다. 개인공간과 협력공간 분리, 자신을 생각을 외현화 할 수 있는 개인 노트, 사고유형 태그 기 능을 지원하고 있다. CoVis는 Pea(2002)가 개발한 도구로 서, 협력적 노트와 과학적 시각화 도구, 탐구활동 말머리 기능을 지원하고 있다([5] 재인용). C-map은 'Insight of Human and Machine Cognition'에서 개념도 생성을 위해 개발된 프로그램으로서 노드와 링크로 인지표상, 메신저 기능을 지원하고 있다.

앞서 제시한 도구들과 참고문헌을 분석한 결과 거시적 스크립트 설계원리는 목표 및 가치를 공유할 있도록 지 원, 과제를 분담할 수 있도록 지원, 일정 및 순서를 관리 할 수 있도록 지원, 개인 및 집단 활동을 통합할 수 있도 록 지원하는 것으로 분석되었다[표 1].

[표 1] 거시적 스크립트 설계원리

[Table 1] design principles of macro-script

\begin{tabular}{c|l}
\hline \multicolumn{1}{c|}{ 설계원리 } & \multicolumn{1}{|c}{ 내용 } \\
\hline \multirow{2}{*}{ 목표 및 가치공유 } & $\begin{array}{l}\text { 공동의 가치에 기반한 목표를 도출하 } \\
\text { 고 목표와 연구문제를 공유할 수 있 } \\
\text { 는 공간 }\end{array}$ \\
\hline 과제 분담 & $\begin{array}{l}\text { 개인과 집단차원에서 어떤 일을, 언 } \\
\text { 제, 누가 수행할 것인지에 대하여 참 } \\
\text { 여자간 작업분담을 지원하는 공간 }\end{array}$ \\
\hline 일정 및 순서관리 & $\begin{array}{l}\text { 작업의 우선순위와 진행정도를 체크 } \\
\text { 하고 공유할 수 있는 공간 }\end{array}$ \\
\hline $\begin{array}{l}\text { 개인 및 집단 활동 } \\
\text { 의 태앙입차원과 집단차원의 작업을 통합 } \\
\text { 할 수 있는 공간 }\end{array}$ \\
\hline
\end{tabular}


거시적 스크립트를 실제로 사용하기 위한 실행원리는 그룹과 개인의 책무성을 가질 수 있도록 지원, 학습자의 문제 해결을 도울 수 있는 다양한 스케폴딩을 제공, 집단 협상 과정을 지원, 구성원간의 전인적 이해를 도울 수 있 도록 지원하는 것으로 분석되었다[표 2].

[표 2] 거시적 스크립트 실행원리

[Table 2] activity principles of macro-script

\begin{tabular}{l|l}
\hline \multicolumn{1}{c|}{ 실행원리 } & \multicolumn{1}{|c}{ 내용 } \\
\hline 그룹과 개인차원의 & $\begin{array}{l}\text { 그룹차원의 목표를 공동의 가치에 기여 수립하고 그룹구성원의 개인적 } \\
\text { 상호 책무됴등을 공동의 목표와 일치시키고 } \\
\text { 서로 공유 }\end{array}$ \\
\hline 다양한 스캐폴드의 & $\begin{array}{l}\text { 학습자의 문제해결 활동을 돕기 위해 } \\
\text { 개념적, 절차적, 전략적 스캐폴딩을 다 } \\
\text { 제공 } \\
\text { 양하게 제공 }\end{array}$ \\
\hline 집단협상의 과정을 & $\begin{array}{l}\text { 학습자 간의 효율적인 업무분담과 일 } \\
\text { 정관리에 대해서 참여자들 간에 토론 } \\
\text { 과 협의를 할 수 있도록 지원 }\end{array}$ \\
\hline $\begin{array}{l}\text { 구성원의 전인적 } \\
\text { 이해 지원즌 가 간의 과제수행 외적인 부분에 } \\
\text { 서 구성원의 선호도, 강점, 약점, 경향 } \\
\text { 성 등을 파악할 수 있도록 지원 }\end{array}$ \\
\hline
\end{tabular}

거시적 스크립트 설계원리 첫째, 목표 및 가치공유이 다. 팀의 과제 목표가 무엇이고 왜 이 목표를 선정하게 되었는지에 대한 팀원의 합의는 프로젝트 수행을 끝까지 완성시키는 추동력이 된다. 둘째, 과제분담이다. 과제분 담에 관한 세부내용을 활자로서 기록해 두는 것은 해당 팀원의 임무를 명확히 할 뿐만 아니라 상호 책임감을 가 질 수 있게 한다. 셋째, 일정 관리 및 순서관리이다. 일정 및 순서 관리에 대한 사전 계획 및 이의 기록은 조정에 있어서 활동의 통합에 따른 혼란을 방지할 수 있고, 과제 수행일정을 기록하게 하는 것은 일의 선후 관계를 명확 하게 하며, 과제수행에 대한 과정을 관리함으로써 더 나 은 성과를 도출할 수 있게 한다. 넷째, 개인 및 집단 통합 이다. 개인 및 다른 팀원들의 과제물에 대한 피드백과 성 찰일지를 작성하게 하여 결과물의 질 향상뿐만 아니라 팀원들간의 상호작용을 촉발하여 활발한 토론 문화를 만 들고자 함이다.

거시적 스크립트의 실행원리 첫째, 그룹과 개인 차원 의 상호 책무성이다. 협력학습의 참여자 개인들이 설정한 목표들을 공유할 수 있도록 함으로써 그룹차원의 목표를 수립할 수 있도록 하며, 이를 통해 그룹의 목표를 달성하 기 위하여 개인적 책무성을 가질 수 있도록 지원해야 한 다. 둘째, 다양한 스케폴딩 제공이다. $\mathrm{CSCL}$ 환경은 학습
자들에게 공유된 학습공간을 제공하여 협력학습을 향상 시킬 수는 있지만, 환경 그 자체만으로는 학습자들 간의 상호작용을 보장해 줄 수는 없다. 예를 들어, 어떤 제안에 대하여 찬성이나 반대를 할 때, 또는 추가적 의견제시나 즉각적 피드백이 없다면 협력학습에 대한 불안감이 생길 수 있다. 따라서 조정지원 환경은 학습자의 문제해결 활 동을 돕기 위해 개념적, 절차적, 전략적 스캐폴딩을 다양 하게 제공할 필요가 있다. 셋째, 집단협상 과정 지원이다. 학습자들 간의 효율적인 업무분담과 일정관리에 대해 참여자들 간에 토론과 협의를 할 수 있도록 지원할 필요 가 있다. 이를 위해서는 전체 일정과 업무를 보여주고, 전 체 속에서 각자의 역할을 어떻게 나누어야 할지, 어떠한 일정으로 과제를 수행할 것인지에 대한 논의를 진행할 수 있도록 해야 할 것이다. 또한 학습자 자신의 역할과 작업진행 정도, 작업의 우선순위를 쉽고 빠르게 체크할 수 있도록 지원해야 한다. 넷째, 구성원의 전인적 이해이 다. 구성원의 전인적 이해란 서로에 대한 정보 예를 들어 선호도, 강점, 약점, 경향성 등을 공유하는 것으로, 이러 한 전인적 이해는 과제수행 시 팀원이 서로를 보완하고, 서로의 행동을 예측하며, 요청하기 전에 정보를 제공하 고, 구성원의 전문성에 따라 자원을 할당하도록 돕는다. 이는 다양한 과제에 공통으로 적용되는 과제 관련 지식 이라고 볼 수 있지만 팀 멤버십이 지속적일 때만 유용한 팀 특화 지식이라고 할 수 있다. 따라서 팀원들 사이에서 과제수행과 관련된 피상적 이해보다는 팀원에 대한 전인 적 이해를 도와 줄 수 있는 환경을 지원하도록 해야 한다.

\section{2 미시적 스크립트 개발 전략 도출}

미시적 스크립트 개발 전략은 역할분담과 관련된 선행 연구 결과를 분석하여 도출하였다. 왜냐하면 $\mathrm{CSCL}$ 환경 에서 역할분담 전략은 그룹 응집력, 책임감, 긍정적인 상 호작용, 개인 책무성에 영향을 미치기 때문이다. 그룹 응 집력은 안정성, 만족감, 효율적인 커뮤니케이션, 사회적 현존감에 긍정적인 영향을 미치며, 그룹 책임감은 그룹의 성과와 상관관계가 있다[15]. 다시 말해서, $\mathrm{CSCL}$ 환경에 서 역할분담 전략은 그룹 구성원간의 커뮤니케이션을 증 가시켜, 학습 결과를 향상시킨다는 의미인 것이다.

$\mathrm{CSCL}$ 환경에서는 교수자와 학습자간, 학습자 상호간 의 학습시간과 장소가 일치될 수 없음을 전제로 하기 때 문에 교수자가 학습과제에 대하여 통제하기가 어렵다. 따 라서 면대면 상황보다 훨씬 더 세밀하고 명시적인 조정 활동이 필요하고, 역할분담에 있어서도 면대면 환경과는 다른 체계가 필요하다. 
[17]은 CSCL 환경에서의 학습자 역할을 조정자 (moderator), 이론가(theoretician), 요약자(summarizer), 정 보수집자(source searcher)으로 구분하였고, [15]는 과제관 련 역할과 사회적 상호작용 관련 역할로 구분하여 제시 하였다. 과제관련 역할에는 조정자, 정보수집자, 종합자, 의견 유도자로 구분하였고, 사회적 상호작용 관련 역할에 는 규칙제정자, 참여촉진자, 조화자, 평가자로 구분하였 다. 위의 연구 결과들을 종합하여 분석하면 표 3 과 같이 정리할 수 있다. 이에 본 연구에서는 미시적 스크립트 개 발 전략으로 과제관련 역할과 활동관련 역할에 근거한 스크립트를 개발하고자 한다.

[표 3] 미시적 스크립트의 설계원리

[Table 3] design principles of micro-script

\begin{tabular}{|c|c|}
\hline 과제관련 & 역할 \\
\hline $\begin{array}{c}\text { 조정자 } \\
\text { (moderator) }\end{array}$ & $\begin{array}{l}\text { 토론 관찰, 속도 조절, } \\
\text { 조언 제공, 답변, 비판적인 질문 유도 }\end{array}$ \\
\hline $\begin{array}{c}\text { 이론가 } \\
\text { (theoretician) }\end{array}$ & $\begin{array}{l}\text { 과제 해결에 관한 이론적 배경 검토 및 피 } \\
\text { 드백 }\end{array}$ \\
\hline $\begin{array}{c}\text { 요약자 } \\
\text { (summarizer) }\end{array}$ & $\begin{array}{l}\text { 팀원들의 제안과 초기 해결책 요약, 차이 } \\
\text { 점 파악, 잠정적인 결론 도출 }\end{array}$ \\
\hline $\begin{array}{l}\text { 정보수집자 } \\
\text { (source } \\
\text { searcher) }\end{array}$ & $\begin{array}{l}\text { 추가적인 자료와 정보 탐색, 교과서의 범 } \\
\text { 위를 넘어설 수 있도록 유도 }\end{array}$ \\
\hline 활동관련 & 역할 \\
\hline $\begin{array}{l}\text { 규칙제정자 } \\
\text { (leader) }\end{array}$ & $\begin{array}{l}\text { 그룹 활동에 필요한 규칙 제정 및 수정, } \\
\text { 변화관리 }\end{array}$ \\
\hline $\begin{array}{l}\text { 참여촉진자 } \\
\text { (facilitator) }\end{array}$ & $\begin{array}{l}\text { 그룹의 토론활동 관찰 및 참여 촉진, 동기 } \\
\text { 부여 }\end{array}$ \\
\hline $\begin{array}{c}\text { 조화자 } \\
\text { (moderator) }\end{array}$ & 그룹 구성원들의 갈등 관리 \\
\hline $\begin{array}{c}\text { 평가자 } \\
\text { (evaluator) }\end{array}$ & 팀원의 활동에 대한 평가 및 보상 \\
\hline
\end{tabular}

활동관련 역할분담 스크립트를 제공한 이유는 다양한 성격의 학습자가 모일 수밖에 없는 CSCL의 사회적 특성 때문이다. 사회적 상호작용(활동) 관련 역할은 그룹 구성 원들 간의 사회적 상호작용 활동에 초점을 맞추어 도출 해 낸 것으로, 이 역할을 맡은 구성원은 동료 구성원을 칭찬하고 격려하는 활동이나 의사소통을 촉진하는 활동, 집단 내 구성원들의 의견을 경청하고 수용하는 활동, 구 성원들 상호간에 친밀감을 형성할 수 있도록 도와주는 활동 등을 하게 된다. 특히, 면대면이 아닌 $\mathrm{CSCL}$ 상황에 서는 훨씬 더 세밀하고 명시적인 조정활동이 필요하기 때문에 이러한 상호작용 역할을 명확하게 해 줄 필요가
있다.

미시적 스크립트는 시스템에서 학습자가 특정 역할을 맡아 수행할 수 있도록 텍스트 형태인 프롬프트 스크립 트 위주로 개발되었으며, 선행적으로 개발된 거시적 스크 립트에서 제공되었다. 스크립트 개발 형태를 프롬프트형 위주로 개발한 이유는 CSCL에서는 수행하는 프로젝트가 창의성과 문제해결력을 필요로 하는 활동이기 때문에 시 스템에서 제공하는 방식을 그대로 따라하는 '따라하기형' 이나 지시사항을 제공받는 '지시형' 스크립트는 과제수 행 상 적절하지 않다고 보았기 때문이다.

\section{3. 조정지원스크립트 개발 결과}

\section{1 거시적 스크립트 개발}

거시적 스크립트는 Windows 2003 Server 운영체제에 기반하여 개발되었다. 데이터베이스는 MS SQL Server 2005 를 사용하였고, 웹 서버는 Windows 2003 Server의 IIS 6.0 을 이용하였다. 프로그램 언어로는 HTML, JavaScript와 ASP, Ajax를 사용하였다. 문헌분석에서 도 출된 거시적 스크립트의 설계원리와 실행원리를 가시화 할 수 있는 지원기능과 지원형식은 표 4와 같다.

[표 4] 거시적 스크립트의 개발 전략

[Table 4] development strategy of macro-script

\begin{tabular}{|c|c|c|}
\hline 설계원리 & \multicolumn{2}{|c|}{ 실행원리 } \\
\hline $\begin{array}{l}\text { 1. 목표 및 가치 } \\
\text { 공유 }\end{array}$ & \multicolumn{2}{|l|}{ 집단협상의 과정을 지원 } \\
\hline 2. 과제 분담 & \multicolumn{2}{|c|}{$\begin{array}{l}\text { 그룹과 개인의 상호책무성 } \\
\text { 구성원의 전인적 이해를 지원 }\end{array}$} \\
\hline $\begin{array}{l}\text { 3. 일정 및 순서 } \\
\text { 관리 }\end{array}$ & \multicolumn{2}{|l|}{$\begin{array}{l}\text { 그룹과 개인의 상호책무성 } \\
\text { 자원의 효율적 활용 }\end{array}$} \\
\hline $\begin{array}{l}\text { 4. 개인 및 집단 } \\
\text { 활동의 통합 }\end{array}$ & \multicolumn{2}{|c|}{$\begin{array}{l}\text { 다양한 스캐폴드 제공 } \\
\text { 상호작용 촉진, 성찰 및 점검지원 }\end{array}$} \\
\hline 설계원리 & 지원기능 & 지원형식 \\
\hline $\begin{array}{l}\text { 1. 목표 및 가치 } \\
\text { 공유 }\end{array}$ & $\begin{array}{l}\text { 의견제시 기능 } \\
\text { 메시징 기능 }\end{array}$ & $\begin{array}{l}\text { 게시판 } \\
\text { SMS }\end{array}$ \\
\hline 2. 과제 분담 & 분업지원 기능 & $\begin{array}{l}\text { 게시판 } \\
\text { 블로그 }\end{array}$ \\
\hline $\begin{array}{l}\text { 3. 일정 및 순서 } \\
\text { 관리 }\end{array}$ & \begin{tabular}{|l} 
일정 관리 기능 \\
작업진척도 관리 기능
\end{tabular} & $\begin{array}{l}\text { 게시판 } \\
\text { 그래프 }\end{array}$ \\
\hline $\begin{array}{l}\text { 4. 개인 및 집단 } \\
\text { 활동의 통합 }\end{array}$ & $\begin{array}{l}\text { 히스토리 관리 기능 } \\
\text { 토론기능 }\end{array}$ & $\begin{array}{l}\text { 게시판 } \\
\text { 댓글, 태그 }\end{array}$ \\
\hline
\end{tabular}


[표 5] 거시적 스크립트 개발 결과

[Table 5] products of macro-script

\begin{tabular}{|c|c|}
\hline 구분 & 지원내용 \\
\hline $\begin{array}{l}\text { 목표 및 } \\
\text { 가치공유 }\end{array}$ & $\begin{array}{l}\text { (집단차원) 팀 과제 목표와 이유를 기술하고 } \\
\text { 공유 } \\
\text { (개인차원) 팀 과제 목표를 학습자의 언어로 } \\
\text { 기술하고 다른 팀원과 비교 }\end{array}$ \\
\hline 과제분담 & $\begin{array}{l}\text { (집단차원) 과제 분담상황을 기술하고 공유 } \\
\text { (개인차원) 본인에게 분담된 과제를 기술하고 } \\
\text { 다른 팀원과 상호확인 }\end{array}$ \\
\hline $\begin{array}{l}\text { 일정 및 } \\
\text { 순서관리 }\end{array}$ & $\begin{array}{l}\text { (집단차원) 과제수행방법을 기술하고 공유 } \\
\text { (집단차원) 과제수행일정을 기술하고 공유 }\end{array}$ \\
\hline $\begin{array}{l}\text { 개인 및 } \\
\text { 집단활동 } \\
\text { 통합 }\end{array}$ & $\begin{array}{l}\text { (집단차원) 다른 팀원들의 과제 결과물 공유 } \\
\text { (개인차원) 자신의 결과물 및 팀원들의 결과물 } \\
\text { 에 대한 피드백 작성하기 }\end{array}$ \\
\hline 구분 & 스크립트 \\
\hline $\begin{array}{l}\text { 목표 및 } \\
\text { 가치공유 }\end{array}$ & $\begin{array}{l}\text { 팀의 과제수행에 있어 최종 목표는 무엇입니 } \\
\text { 까? } \\
\text { 팀의 과제 선정 이유는 무엇입니까? } \\
\text { 귀하가 속한 팀의 과제수행에 있어 최종 목표 } \\
\text { 는 무엇입니까? 기재한 후에는 다른 팀원의 생 } \\
\text { 각과 일치하는지 비교해서 수정하시기 바랍니 } \\
\text { 다. }\end{array}$ \\
\hline 과제분담 & $\begin{array}{l}\text { 팀 과제 수행 시 세부과제의 수행주체와 내용 } \\
\text { 을 입력하세요. } \\
\text { 팀 작업에서 귀하에게 분담된 작업은 무엇입 } \\
\text { 니까? 기재한 후에는 다른 팀원의 작업을 확인 } \\
\text { 하고 적정하게 분담이 되었는지 체크하시기 } \\
\text { 바랍니다. }\end{array}$ \\
\hline $\begin{array}{l}\text { 일정 및 } \\
\text { 순서관리 }\end{array}$ & $\begin{array}{l}\text { 과제 수행을 어떻게 할 것인지 로드맵을 그려 } \\
\text { 보세요. } \\
\text { 과제 수행 일정을 입력하세요. }\end{array}$ \\
\hline $\begin{array}{l}\text { 개인 및 } \\
\text { 집단활동 } \\
\text { 통합 }\end{array}$ & $\begin{array}{l}\text { 다른 팀원들의 과제 결과물에 대한 피드백을 } \\
\text { 입력하세요 } \\
\text { 자신의 과제 결과물에 대한 피드백 및 성찰일 } \\
\text { 지를 작성하세요. }\end{array}$ \\
\hline
\end{tabular}

표 5는 거시적 스크립트 개발 결과를 요약한 내용이 다. 거시적 스크립트는 과제수행계획을 수립할 때 제공된 다. 과제수행의 초기 단계에서 각 항목별로 직접 입력하 게 하고 상황에 따라 수정할 수 있게 함으로써 팀 활동의 목표와 내용을 명확하게 인식하게 하는 기능을 한다.

\section{2 미시적 스크립트 개발}

미시적 스크립트는 과제관련역할과 활동관련역할로 구분하여 개발하였으며, 내용은 표6,표7과 같다.

과제관련역할 스크립트는 과제수행의 초기 단계에서 팀의 과제수행 목표와 본인에게 분담된 과제와 역할이 무엇인지 직접 기술해 보게 하고, 다른 팀원의 기재 내용
과 비교하여 합의된 사항이 맞는지 확인하게 하는 기능 을 한다. 또한 팀의 과제수행과 관련한 본인의 역할이 무 엇인지 레이블을 통해서 인지하고 구체적인 활동계획을 입력해 봄으로써 본인의 역할인식을 명확하게 하는 기능 을 제공한다. 과제관련역할 스크립트는 조정자, 이론가, 요약자, 정보수집자로 구분하였다.

활동관련역할 스크립트는 과제관련역할 스크립트와 마찬가지로 과제수행계획을 수립할 때 제공되며, 설정된 역할에 따라 각기 다른 스크립트가 표시된다. 활동관련역 할 스크립트는 규칙제정자, 참여촉진자, 평가자, 조화자 로 구분하였다.

[표 6] 미시적 스크립트 개발 결과-과제관련역할

[Table 6] products of micro-script(task role)

\begin{tabular}{|c|c|c|}
\hline & 분 & 지원내용 \\
\hline \multirow{4}{*}{$\begin{array}{l}\text { 과 제 } \\
\text { 관련 }\end{array}$} & 조정자 & $\begin{array}{l}\text { 토론 관찰, 속도 조절, } \\
\text { 조언 제공, 답변, 비판적인 질문 유도 }\end{array}$ \\
\hline & 이론각 & $\begin{array}{l}\text { 과제 해결에 관한 이론적 배경 검토 및 피 } \\
\text { 드백 }\end{array}$ \\
\hline & 요약자 & $\begin{array}{l}\text { 팀원들의 제안과 초기 해결책 요약, 차이 } \\
\text { 점 파악, 잠정적인 결론 도출 }\end{array}$ \\
\hline & \begin{tabular}{|l|} 
정보 \\
수집자 \\
\end{tabular} & $\begin{array}{l}\text { 추가적인 자료와 정보 탐색, 교과서의 범 } \\
\text { 위를 넘어설 수 있도록 유도 }\end{array}$ \\
\hline & 구분 & 스크립트 \\
\hline $\begin{array}{l}\text { 과 제 } \\
\text { 관련 }\end{array}$ & 조정자 & $\begin{array}{l}\text { 팀 과제와 관련한 귀하의 역할은 조정자입 } \\
\text { 니다. 조정자로서 귀하는 구체적으로 어떤 } \\
\text { 활동을 계획하고 계십니까? } \\
\text { (입력예시) 이야기가 주제에서 벗어나지 } \\
\text { 않도록 하겠다. } \\
\text { (대화예시) "이 부분은 좀 더 자세히 애기 } \\
\text { 해 보자" }\end{array}$ \\
\hline \multirow{3}{*}{$\begin{array}{l}\text { 과 제 } \\
\text { 관련 }\end{array}$} & 이론 & $\begin{array}{l}\text { 팀 과제와 관련한 귀하의 역할은 이론가입 } \\
\text { 니다. 이론가로서 귀하는 구체적으로 어떤 } \\
\text { 활동을 계획하고 계십니까? } \\
\text { (입력예시)과제수행내용이 타당한지 다각 } \\
\text { 적 검토와 질문을 하겠다. } \\
\text { (대화예시) "그 주장의 근거는 무엇인가 } \\
\text { 요?" }\end{array}$ \\
\hline & 요약자 & $\begin{array}{l}\text { 팀 과제와 관련한 귀하의 역할은 요약자입 } \\
\text { 니다. 요약자로서 귀하는 구체적으로 어떤 } \\
\text { 활동을 계획하고 계십니까? } \\
\text { (입력예시)팀원들의 토론내용을 요약하고 } \\
\text { 맞는지 팀원들에게 확인하겠다. } \\
\text { (대화예시) "오늘 우리의 회의 내용을 정 } \\
\text { 리하면 다음과 같습니다." }\end{array}$ \\
\hline & $\begin{array}{l}\text { 정보 } \\
\text { 수집자 }\end{array}$ & $\begin{array}{l}\text { 팀 과제와 관련한 귀하의 역할은 정보수집 } \\
\text { 자입니다. 정보수집자로서 귀하는 구체적 } \\
\text { 으로 어떤 활동을 계획하고 계십니까? } \\
\text { (입력예시)과제수행 관련 자료를 충분히 } \\
\text { 찾겠다. } \\
\text { (대화예시) "이 자료처럼 이런 방식도 좋 } \\
\text { 을 것 같은데..어때?" }\end{array}$ \\
\hline
\end{tabular}


[표 7] 미시적 스크립트 개발 결과-활동관련역할 [Table 7] products of micro-script(activity role)

\begin{tabular}{|c|c|c|}
\hline & 구분 & 지원내용 \\
\hline \multirow{4}{*}{$\begin{array}{l}\text { 활 } \\
\text { 동 } \\
\text { 관 } \\
\text { 련 }\end{array}$} & $\begin{array}{l}\text { 규칙 } \\
\text { 제정자 }\end{array}$ & $\begin{array}{l}\text { 그룹 활동에 필요한 규칙 제정 및 수정, 변 } \\
\text { 화관리 }\end{array}$ \\
\hline & $\begin{array}{l}\text { 참여 } \\
\text { 촉진자 }\end{array}$ & $\begin{array}{l}\text { 그룹의 토론활동 관찰 및 참여 촉진, 동기 } \\
\text { 부여 }\end{array}$ \\
\hline & 조화자 & 그룹 구성원들의 갈등 관리 \\
\hline & 평가자 & 팀원의 활동에 대한 평가 및 보상 \\
\hline & 구분 & 지원내용 \\
\hline \multirow{4}{*}{$\begin{array}{l}\text { 활 } \\
\text { 동 } \\
\text { 관 } \\
\text { 련 }\end{array}$} & $\begin{array}{l}\text { 규칙 } \\
\text { 제정자 }\end{array}$ & $\begin{array}{l}\text { (입력예시) 주어진 시간과 자원을 고려하 } \\
\text { 여 합리적인 일정을 수립하겠다. } \\
\text { (대화예시) "적어도 하루에 하나의 자료를 } \\
\text { 찾아서 올리자" }\end{array}$ \\
\hline & $\begin{array}{l}\text { 참여 } \\
\text { 촉진자 }\end{array}$ & $\begin{array}{l}\text { (입력예시)팀원들이 의욕적으로 과제를 수 } \\
\text { 행하도록 기분을 즐겁게 하겠다. } \\
\text { (대화예시) "그것을 하는 사람은 } 00 \text { 를 면 } \\
\text { 제해 주면 어떨까?" }\end{array}$ \\
\hline & 조화자 & $\begin{array}{l}\text { (입력예시)팀원들 간 갈등요소를 사전에 } \\
\text { 파악하여 제거하겠다. } \\
\text { (대화예시) "자자 흥분을 가라앉히고 차근 } \\
\text { 차근 살펴보자고.." }\end{array}$ \\
\hline & 평가자 & $\begin{array}{l}\text { (입력예시)열심인 팀원에게 칭찬을 많이 } \\
\text { 하겠다. } \\
\text { (대화예시) "A군의 활동에 대해서 우리 박 } \\
\text { 수 한 번 쳐줍시다." }\end{array}$ \\
\hline
\end{tabular}

\section{4. 효과 분석 및 논의}

\section{1 효과 분석 방법}

개발된 조정지원스크립트의 효과는 공유정신모형으로 분석하였으며, 학습활동과 학습결과로 구분하여 분석하 였다. 학습활동은 과제수행 공유정신모형 설문으로 분석 하였고, 학습결과는 과제포트폴리오를 분석하였다.

학습활동 분석 도구인 과제수행 공유정신모형은 [8]의 연구에서 활용한 설문도구를 본 연구에 맞게 수정·보완하 여 사용하였으며, 본 연구에서 사용한 설문문항의 Cronbach $\alpha$ 계수는 .937이였다. 설문내용은 목표 공유, 일정관리, 역할분담, 활동통합의 내용이였으며, 5 점 평점 척도를 사용하였다. 설문조사는 과제수행 후 7일이 경과 한 뒤 1 차 공유정신모형 설문조사, 14 일이 경과한 후 2 차 공유정신모형 설문을 실시하였다.

학습결과 분석 도구인 과제포트폴리오는 팀별 프로젝 트를 통하여 ‘업무성과의 혁신을 위한 프로젝트 보고서 1 차, 2 차'를 작성하게 하고, 이에 대한 평가를 실시하였다. 과제수행 기간은 30 일 동안 진행되었으며, 팀별 프로젝
트 결과물로 과제 포트폴리오를 제출하였다. 과제 포트폴 리오 평가는 100 점을 만점으로 하되 Y 회사 사업부서장 급 이상 관리자 5 명과 교육공학 박사 2 명, 경영컨설턴트 1 인의 평균점수로 계산되었다. 포트폴리오 평가기준은 [5]의 연구에서 사용한 기준을 적용하였으며, Y 회사 사 업부서장급 이상의 직위에 있는 3 명과 경영학 박사학위 소지자인 경영컨설턴트 1 인에게 검토를 받았다.

분석 대상은 서울에 소재한 $\mathrm{Y}$ 중소기업 48 명 직원들 을 대상으로 하였다. 이 회사의 직원들의 경우 지식산업 과 관련된 출판, 교육, 인터넷 사업을 운영하기 때문에 직 원들이 웹 문화와 컴퓨터를 사용하는 소양은 다소 높은 편이다. 거의 모든 업무가 컴퓨터작업과 온라인으로 이루 어지기 때문에 CSCL환경에 적응하는 것은 그리 어렵지 않으므로 효과성 분석 대상으로 적정하다고 판단되었다.

실험집단은 총 48 명을 대상( 팀별 4 인씩 총 12 개팀 구 성)으로 . 조정지원 스크립트를 제공받은 실험집단에 24 명 6개조, 통제집단에 24명 6개조를 무선 배치하였다. 실 험에 참가한 학습자들은 이전에 프로젝트에 참가한 경험 이 없고 이들을 무선 배치하였기 때문에 동질 집단으로 가정하였다.

본 연구에서 제공한 조정지원환경은 개인학습실, 학습 토론실, 공동학습실이 최상위 매뉴로 구성되었으며, 각각 의 서브매뉴로 각종 안내 게시판, 계획하기 게시판, 자료 실, 일정관리, 연락하기 등으로 구성되었다. 주요 기능으 로 쓰기, 수정, 말머리, 태그, 댓글, 평가, SMS 등이 제공 되었다.

\section{2 효과 분석 결과}

\subsection{1 학습활동 차이검증(과제수행 공유정신모형 분석)}

집단에 따른 1 차 과제 수행 공유정신모형 점수 분석 결과[표 8]에 따르면 통계적으로 유의미한 차이가 있는 것으로 나타났으며 $(\mathrm{t}(46)=2.89, \mathrm{p}=.00), \quad 2$ 차 과제 수행 공유정신모형 점수 분석 결과[표 9]에서도 통계적으로 유 의미한 차이가 있는 것으로 나타났다 $(\mathrm{t}(46)=2.26, \mathrm{p}=.03)$

[표 8] 1차 공유정신모형 점수 t-test

[Table 8] t-test of the first shared mental model

\begin{tabular}{c|c|c|c|c|c|c}
\hline 변수 & 집단 & $\begin{array}{c}\text { 사례 } \\
\text { 수 }\end{array}$ & 평균 & $\begin{array}{c}\text { 표준편 } \\
\text { 차 }\end{array}$ & $\mathrm{t}$ & $\mathrm{p}$ \\
\hline $\begin{array}{c}\text { 1차 } \\
\text { 공유정 }\end{array}$ & $\begin{array}{c}\text { 스크립트 } \\
\text { 제공집단 }\end{array}$ & 24 & 109.44 & 8.27 & 2.89 & .00 \\
\cline { 2 - 6 } 신모형 & 통제집단 & 24 & 100.42 & 7.63 & & \\
\hline
\end{tabular}


[표 9] 2차 공유정신모형 점수 t-test

[Table 9] t-test of the second shared mental model

\begin{tabular}{|c|c|c|c|c|c|c|}
\hline 변수 & 집단 & 사례수 & 평균 & 표준편차 & $\mathrm{t}$ & $\mathrm{p}$ \\
\hline $\begin{array}{l}2 \text { 차 } \\
\text { 공유 }\end{array}$ & $\begin{array}{l}\text { 스크립트 } \\
\text { 제공집단 }\end{array}$ & 24 & 113.31 & 9.22 & \multirow{2}{*}{2.26} & \multirow{2}{*}{.03} \\
\hline $\begin{array}{l}\text { 정신 } \\
\text { 모형 }\end{array}$ & 통제집단 & 24 & 103.50 & 8.21 & & \\
\hline
\end{tabular}

\subsection{2 학습결과 차이검증(과제포트폴리오분석)}

과제 포트폴리오 평가는 업무성과혁신 과제에 관한 보 고서를 작성하게 하고, 이에 대한 평가를 2회(1차, 2차) 실시하였다. 집단 간 1 차 팀 과제 포트폴리오 점수 분석 결과[표 10] 통계적으로 유의미한 차이가 없는 것으로 나 타났으며 $(\mathrm{t}(10)=1.75, \mathrm{p}=.11)$, 집단 간 2 차 팀 과제 포트폴 리오 점수 분석 결과[표 11] 통계적으로 유의미한 차이가 없는 것으로 나타났다 $(\mathrm{t}(10)=1.70, \mathrm{p}=.12)$.

[표 10] 집단 간 1차 팀 과제 포트폴리오 점수 t-test [Table 10] t-test of the first team project portfolio between group

\begin{tabular}{|c|c|c|c|c|c|c|}
\hline 변수 & 집단 & 사례수 & 평균 & 표준편차 & $\mathrm{t}$ & $\mathrm{p}$ \\
\hline $\begin{array}{c}1 \text { 차 } \\
\text { 팀 과제 }\end{array}$ & $\begin{array}{l}\text { 스크립트 } \\
\text { 제공집단 }\end{array}$ & 6 & 63.88 & 8.78 & \multirow[b]{2}{*}{1.75} & \multirow[b]{2}{*}{.11} \\
\hline $\begin{array}{c}\text { 포트 } \\
\text { 폴리오 } \\
\text { 점수 }\end{array}$ & 통제집단 & 6 & 53.00 & 11.26 & & \\
\hline
\end{tabular}

* 사례수 : 4 명 1 팀으로 총 12 개 팀의 과제

[표 11] 집단 간 2차 팀 과제 포트폴리오 점수 t-test [Table 11] t-test of the second team project portfolio between group

\begin{tabular}{|c|c|c|c|c|c|c|}
\hline 변수 & 집단 & 사례수 & 평균 & 표준편차 & $t$ & $\mathrm{p}$ \\
\hline \multirow{2}{*}{$\begin{array}{c}\text { 2차 } \\
\text { 팀 과제 } \\
\text { 포트 } \\
\text { 폴리오 } \\
\text { 점수 }\end{array}$} & $\begin{array}{l}\text { 스크립트 } \\
\text { 제공집단 }\end{array}$ & 6 & 73.78 & 15.67 & \multirow{2}{*}{1.70} & \multirow{2}{*}{.12} \\
\hline & 통제집단 & 6 & 56.33 & 14.22 & & \\
\hline
\end{tabular}

조정지원 스크립트의 제공 여부가 팀 과제 포트폴리오 점수의 향상에 영향을 미쳤는지 알아보기 위하여 스크립 트를 제공받은 집단의 1,2 차 팀 과제의 점수를 분석한 결과[표12] 2차 팀 과제 포트폴리오 점수의 평균이 1차 팀 과제 포트폴리오 점수의 평균 보다 9.89 높았으며 이 차이는 통계적으로 유의미하였다 $(\mathrm{t}(10)=3.07, \mathrm{p}=.02)$.
[표 12] 조정지원 스크립트 제공집단의 과제 포트폴리오 t-test

[Table 12] $t$-test of $t$ team project portfolio between provided with coordination supporting script group

\begin{tabular}{c|c|c|c|c|c}
\hline & 사례수 & 평균 & 표준편차 & $\mathrm{t}$ & $\mathrm{p}$ \\
\hline $\begin{array}{c}\text { 1차 팀 } \\
\text { 과제점수 }\end{array}$ & 6 & 63.88 & 8.78 & \multirow{2}{*}{3.07} & .02 \\
$\begin{array}{c}\text { 2차 팀 } \\
\text { 과제점수 }\end{array}$ & 6 & 73.78 & 15.67 & & \\
\hline 차이 & & 9.89 & 9.68 & & \\
\hline
\end{tabular}

\section{3 효과 분석에 관한 논의}

조정지원스크립트가 공유정신모형 구축에 어떠한 영 향을 미치는 지를 검증한 결과, 첫째, 과제수행 공유정신 모형에서는 스크립트 제공이 과제를 수행 하는 과정에서 상호작용을 활발하게 하여 공유정신모형을 구축하는데 긍정적인 영향을 주었다. 이러한 연구 결과는 $[3,12,17]$ 의 연구 결과와 일치하였다. 조정지원스크립트가 학습자들 로 하여금 개인단위의 작업과 공동 작업의 적절한 조화 를 이룰 수 있도록 지원한 것으로 해석할 수 있다. 또한 학습자 개인의 역할에 따른 적절한 미시적 스크립트 제 시와 목표를 공유한다던지, 과제를 수행하는 일정과 순서 를 관리할 수 있는 등의 거시적 스크립트 제시가 상보적 인 효과를 미치는 것을 알 수 있었다.

둘째, 학습 결과인 과제 포트폴리오를 분석할 결과 스 크립트 제시한 집단과 통제 집단 간의 유의미한 결과는 없었으며, 학습활동과 학습 결과에 있어 일치되지 않은 결과가 나타났다. 이러한 결과는 실험 과정에서의 문제점 때문일 것이다. 실험 대상들이 익숙하지 않은 프로젝트 성 과제 때문에 과제 수행 시 조정활동에 초점을 두기 보 다는 프로젝트에 대한 이해를 먼저 하느라 우왕좌왕한 모습들이 보였다. 이는 학교가 아닌 현장에서 실험연구를 할 경우 수행과제의 친숙성과 수행기간의 확보에 주의를 기울여야 함을 시사한다.

셋째, 2 차 팀 과제 포트폴리오 점수의 표준편차를 살 펴보면 1 차 경우에 비해 현저하게 증가한 것으로 나타났 다. 이러한 결과는 실험 기간이 경과함에 따라 팀 별 역 량의 문제점 때문일 것이다. 실험 대상자들이 1 차 실험 시에는 처음 접해 본 환경과 과제로 동기유발이 되어 과 제의 질이 6 개의 팀 과제 점수 차이가 않았지만, 2 차 실 험 시에는 집중도가 떨어지는 현상을 보여 팀별로 과제 점수 차이가 큰 것으로 보여진다. 이는 현장에서 실험연 구를 할 경우에는 수행기간의 선정에 주의를 기울여야 
함을 시사한다.

넷째, 학습 결과에 대한 집단 간의 차이는 없었지만, 조정지원스크립트를 제공받은 집단의 1 차, 2 차의 과제포 트폴리오의 점수에는 통계적으로 유의미한 결과가 있었 다. 이는 학습자들이 시간이 경과함에 따라 조정스크립트 를 내재화되어 2차 과제 수행 시에는 좀 더 수월하게 상 호작용을 할 수 있게 되었음을 의미한다.

다섯째, 학습결과 효과를 검증한 결과 1,2 차 모두 유의 미한 결과가 없는 것으로 나타났다. 이러한 결과는 표본 수의 문제로 인해 통계적인 유의미성이 나타나지 않는 것으로 해석할 수 있을 것이다. 이에 통계적 유의성이 아 닌 실제적 유의성을 고려한다면 effect size의 경우 1차 $0.96,2$ 차 1.22 로 실제적 유의성이 있는 것으로 나타났다. 이는 실질적으로 거시적 스크립트와 미시적 스크립트의 동시 사용이 학습결과인 과제 포트폴리오에 영향을 미칠 수 있는 변인임을 시사한다.

\section{5. 결론 및 제언}

본 연구는 $\mathrm{CSCL}$ 에서 공유정신모형 구축에 필수적인 조정활동을 지원하는 조정지원스크립트를 개발하고 효과 를 분석하여 학습 환경 설계를 위한 실제적인 시사점을 제시하고자 하였다. 기존의 조정지원스크립트가 간과하 고 있는 거시적, 미시적 스크립트 속성을 반영하기 위해 조정환경 분석을 통해 거시적 스크립트 설계전략을 도출 하였고, 역할 분담과 관련된 문헌 분석을 통해 미시적 스 크립트 설계전략을 도출하였다.

거시적 스크립트는 목표 및 가치공유, 과제분담, 일정 및 순서 관리, 개인 및 집단 활동의 통합에 따라 스크립 트를 개발하였고, 미시적 스크립트는 과제관련 역할(조정 자, 이론가, 요약자, 정보수집자)과 활동관련 역할(규칙제 정자, 참여촉진자, 조화자, 평가자)에 따라 개발하였다.

개발된 조정지원스크립트의 효과는 공유정신모형(과 제 수행 공유정신모형 설문, 과제포트폴리오) 구축에 미 치는 영향으로 분석하였다. CSCL에서 조정지원스크립가 과제 수행 공유정신모형에 미치는 영향을 분석한 결과 1 차, 2 차 공유정신모형 측정 점수는 조정지원 스크립트를 제공받은 집단과 통제 집단간 유의미한 차이가 있는 것 으로 나타났다. 과제포트폴리오 측정 점수는 1차, 2 차 모두 두 집단의 차이는 유의미하지 않았다. 그러나 조정 지원 스크립트 제공집단의 1,2 차 팀 과제 포트폴리오 점 수의 평균을 비교한 결과 2 차 팀 과제 포트폴리오 점수의
평균이 1차 팀 과제 포트폴리오 점수의 평균 보다 높았으 며, 유의미한 차이를 나타냈다.

본 연구 결과는 거시적 스크립트와 미시적 스크립트를 함께 제공하는 것은 공유정신모형 구축의 과정에 상보적 인 효과가 있음을 시사한다.

후속 연구를 위한 제언을 제시하면 다음과 같다.

첫째, 거시적 스크립트는 미시적 스크립트와 상보적 관계를 형성하므로 학습자가 선호하는 학습전략, 선수 능 력 및 기술 수준에 따라 개별화된 적응적 스크립트를 제 시할 필요가 있다. 이를 위해서는 미시적 스크립트를 보 완, 촉진할 수 있는 스크립트 설계 및 다양한 스크립트 요소들과의 상호작용에 관해 지속적으로 탐색해야 한다.

둘째, 연구 설계와 관련하여 과제의 친숙성에 대한 것 이다. 본 연구대상자들에게 프로젝트 형 과제는 생소하였 기에 실험 초반 조정활동에 초점을 두기 보다는 프로젝 트 과제 유형에 대한 이해하는데 시간을 소비하는 모습 들을 보였다. 이는 학교가 아닌 현장에서 실험연구를 할 경우 수행과제의 친숙성과 수행기간을 확보해야 함을 의 미한다.

\section{References}

[1] Bromme, R., Hesse, F. W., \& Spada, H.(Eds.). Barriers and biases in computer-mediated knowledge communication - and how they may be overcome. New York, NY: Springer. 2005.

[2] Cannon-bowers, J. A., \& Salas, E.. Reflections on shared cognition. Journal of organizational behavior, 22(2), pp 195-202, 2001.

[3] Dillenbourg, P., Hong, F. \& Brahm, T. The ManyScripts Pedagogical Handbook: How to build scripts for collaborative learning?. In Manyscripts A tool by EPFL Retrieved from http://manyscripts.epfl.ch/documents. discussion groups?. Computer-Supported Collaborative Learning, 2(2-3), pp 225-246, 2006.

[4] Dillenbourg, P., \& Tchounikine, P. Flexibility in macro-scripts for computer-supported collaborative learning. Journal of Computer Assisted Leaning, 23, pp 1-13, 2008.

[5] Dong kwon Oh. Design-Based Research of Coordination Supporting Tool for Collaboration Inquiry Activity in CSCL Hanyang University, doctoral dissertation. 2008.

[6] Dongsjk Kim, Sookjin, Kweon). The effects of scaffolding types on the forming shared mental model 
in CSCL. Jounal of Educational Technology. 22(1), pp 1-34, 2000.

[7] Engeström, Y. Activity theory and transformation, In Engeström, Y, Miettinen, R, \& Punamaki, R(Ed.), 19-38, Perspectives on Activity Theory, UK: Cambridge University. 1999a.

[8] Hyun song Kim. The effects of the coordination supporting tool types on shared mental models and team activity. Hanyang University. 2007.

[9] King, A.. Scripting collaborative learning processes: A cognitive perspective. Computer-Supported Collaborative Learning 2: pp 13-37, 2007.

[10] Kobbe, L., Weinberger, A., Dillenbourg, P., Harrer, A., Hamalainen, R., Hakkinen, P., \& Fischer, F. Specifying computer-supported collaboration scripts. Intl. J. of CSCL, 2(2\&3). pp 211-224, 2007.

[11] Lee.J. SIBYL: a tool for managing group decision rationale. Proceedings of Computer-Supported Cooperative work pp.79-92, 1990.

[12] Rummel, N., \& Spada, H. Learning to collaborate : an instructional approach to promoting collaborative problem solving in computer-mediated settings. J. of learning sciences, 14(2), pp 201-241, 2005.

[13] Scardamalia, M.. CSILE/Knowledge Forum. In Education and technology : An encyclopedia(p.183-192). Santa Barbara, CA:ABC-CLIO. 2004.

[14] Schellens, T., Keer, V. H., \& Wever, B. D. Scripting by assigning roles : Does it improve knowledge construction in asynchronous Computer-Mediated Settings. Journal of the Learning Sciences, 14(2), pp 201-224, 2007.

[15] Soohyun Kim. The effects of assigned role strategy on the shared mental model and communication in CSCL. The korea Jounal of the Learning Science. 4(1), pp 27-48, 2010.

[16] Stoyanova, N, \& Kommers. P. learning effectiveness of concept mapping in a computer supported collaborative problem solving design. 2001. Euro CSCL Conference Proceedings. 2001.

[17] Tammy, S., Kerr, H., Wever, B., \& Valcke, M. Scripting by assigning roles: does it improve knowledge construction in asynchronous groups? Intl. J. of CSCL, 2(2\&3). pp 224-246, 2007.

[18] Veermans, M., Lallimo, J., \& Hakkarainen, K. Patterns of guidance in inquiry learning. J. of interactive learning research. 19(2), pp 179-194, 2005.

[19] Young min Lee. The effects of shared mental model on learners and team performance in web-based team learning enviroment. Jounal of Educational Technology, 21(3), pp 79-9,. 2005.

\section{김 수 현(Soo hyun Kim)}

[정회원]

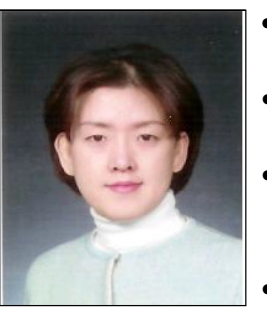

1999년 2월 : 한양대학교 가정관 리학과(가정학 석사)

- 2009년 2월 : 한양대학교 교육공 학과(교육학 박사)

- 2009년 3월 2009년 12월 : 한 양대학교 교육공학과 $\mathrm{BK}$ Post Doc.

- 2010년 3월 현재 : 거제대학 교 유아교육과 교수

<관심분야>

교육학, 교수설계, $\mathrm{HRD}$ 